\title{
Gastro-Esophageal Reflux and Pulmonary Medicine; Where Are We and What Should We Do?
}

\section{Mostafa Ghanei* and Amin Saburi \\ Chemical Injury Research Center, Baqiyatallah University of Medical Sciences, Tehran, I.R. Iran}

There is growing concern about relation between GastroEsophageal Reflux Disease (GERD) and pulmonary diseases. It seems that researches which are focused on pulmonary effects of GERD are now being enhanced during the past decades. GERD is one of the commonest gastrointestinal disorders which is affecting more than one/forth of adults in western countries [1]. Recently, the prevalence of GERD is rising especially in developing countries. The same entities of some diseases have been recognized especially when the organs have the same embryonic origin [2]. Accordingly, the same originality of airways and esophagus can explain the pathogenesis of the both GERD and pulmonary related disorders. Also, there are evidences about the relation between airway narrowing and esophageal distention due to intra-esophageal hydrochloric acid provocation via vague nerve [2,3]. Accompanying between these two diseases especially in incidences and responses to the treatment enhance this hypothesis.

The role of gastric especially acidic contents in pulmonary complication of GERD has been identified well. Increase in exhaled oxidative stress biomarkers (e.g, 8-isoprostane), neuroinflammation increases in vagal tone and $\mathrm{PH}$ metery findings in especially symptomatic patients are considered as some evidence in the pathogenic role of acid reflux in GERD [4].

Aspiration of non acidic gastric contents such as pepsin, pepsinogen, pancreatic enzymes and bile derivates have been also reported to play a role in pulmonary symptoms of asthma $[5,6]$. Increasing in some pro-inflammatory cytokine such as IL-8 was detected in bronchial epithelial cells of patients who are under acid suppressive treatment. These evidences support this theory that the non-acidic component reflux may induce inflammatory responses of lung to GERD. Although reaction to the microbial agents or endotoxins in the gastric content may even induce the pulmonary inflammatory responses, it has not been yet identified which part of the gastric content has more significant influence on the respiratory epithelium [7]. Asthma, chronic cough, chronic bronchitis, bacterial pneumonia and interstitial lung fibrosis are well determined as pulmonary consequences of GERD [1].

However still some questions have been remained to be answered in this filed before designing an effective therapeutic protocol. Traditional treatments of GERD reduce acid related symptoms in these patients although the injury of non-acidic reflux can be continued and consequently the symptoms persist. Regarding to the failure of traditional anti reflux medication in many cases, new therapeutic agents should be considered in future studies. New generation of anti-reflux medications such as MGluR5 antagonists and $\gamma$-Amino butyric acid agonists have been recommended which is affecting the transient lower esophageal sphincter relaxation that is the basic underlying cause of reflux [8]. On the other side, GERD is regularly diagnosed and treated in only symptomatic stage. However the "silent" form of disease which can be associated with microaspiration usually is neglected.

The low effectiveness of current remedies to suppress gastric acidity even with powerful proton pump inhibitors on extra-esophageal symptoms of GERD may suggest that reflux can exert its effects through mechanisms beyond excessive acid production. Non acidic component reflux was presented as a justifying mechanism for extra-esophageal symptoms of patients who were remained unresponsive to acid suppressive treatment [9]. Symptomatic relief in response to surgical repair of lower esophageal sphincter that targets the basic mechanism of reflux as a motility disorder can support this idea [10]. The symptoms of high acid reflux can be controlled by acid suppressive treatment but the Pathophysiology remains intact. Accordingly, we need to an effective marker or device to evaluate the efficacy of treatment especially in non-acidic reflux although bile salts or pepsin of sputum was faintly introduce as diagnostic biomarkers for GERD. Also, the neural reflex between the esophagi sensitizes and cough reflex in patients with GERD and chronic cough was previously described [11]. Therefore, Even if the aspiration (micro or macro) is controlled in patients with reflux, the symptoms may not relief although microaspiration can be difficult to control and monitor.

Bronchiolitis obliterans is the main cause of lung transplant rejection and the microaspiration has been implicated as the latent causative factor leading to Bronchiolitis obliterans in this patients [12].

Also, we need studies which evaluate the efficacy of microaspiration treatment on the extra-pulmonary manifestations of GERD to confirm the role of any degree of reflux in pathogenesis of GERD in lung tissue. In addition, there are no methods for following up of treatment's efficacy and it can be proposed for future studies. There are some biomarkers increased in respiratory system of patients with GERD which it can be useful for this issue. For example substance $\mathrm{P}$ and neurokinin $\mathrm{A}$ are increasing in response of inflammatory process at the respiratory epithelium [13]. Salivary or sputum pepsin and pepsinogen level can be measured for this issue as well. It seems that replacing PH metery with another diagnostic and confirming method is helpful to achieve to more accurate diagnosis in non-acidic gastro esophageal reflux.

\section{References}

1. Pearson JP, Parikh S, Orlando RC, Johnston N, Allen J, et al. (2011) Review article: reflux and its consequences--the laryngeal, pulmonary and oesophageal manifestations. Conference held in conjunction with the 9th International Symposium on Human Pepsin (ISHP) Kingston-upon-Hull, UK, 21-23 April 2010. Aliment Pharmacol Ther 33: 1-71.

2. Jadcherla SR (2006) Upstream effect of esophageal distention: effect on airway Curr Gastroenterol Rep 8: 190-194.

3. Mansfield LE, Hameister HH, Spaulding HS, Smith NJ, Glab N, et al. (1981) The role of the vague nerve in airway narrowing caused by intraesophageal hydrochloric acid provocation and esophageal distention. Ann Allergy 47: 431-434.

4. Shimizu Y, Dobashi K, Zhao JJ, Kawata T, Ono A, et al. (2007) Proton pump inhibitor improves breath marker in moderate asthma with gastroesophageal reflux disease. Respiration 74: 558-564.

*Corresponding Author: Prof. Mostafa Ghanei, Pulmonologist, Chemica Injury Research Center, Baqiyatallah University of Medical Sciences, Mollasadra St, Vanak Sq, Tehran, I.R. Iran, Tel/Fax: +98-21-88600067; E-Mail: mghaneister@gmail.com

Received March 13, 2012; Accepted March 16, 2012; Published March 18, 2012

Citation: Ghanei M, Saburi A (2012) Gastro-Esophageal Reflux and Pulmonary Medicine; Where Are We and What Should We Do?. J Pulmonar Respirat Med 2:e107. doi:10.4172/2161-105X.1000e107

Copyright: ( 2012 Ghanei M, et al. This is an open-access article distributed under the terms of the Creative Commons Attribution License, which permits unrestricted use, distribution, and reproduction in any medium, provided the original author and source are credited. 
Citation: Ghanei M, Saburi A (2012) Gastro-Esophageal Reflux and Pulmonary Medicine; Where Are We and What Should We Do?. J Pulmonar Respirat Med 2:e107. doi:10.4172/2161-105X.1000e107

5. Asano K, Suzuki H (2009) Silent acid reflux and asthma control. N Eng J Med 360: 1551-1553.

6. Canning BJ, Mazzone SB (2003) Reflex mechanisms in gastroesophageal reflux disease and asthma. Am J Med 115: 45-48.

7. Mertens V, Blondeau K, Vanaudenaerde B, Vos R, Farre R, et al. (2010) Gastric juice from patients "on" acid suppressive therapy can still provoke a significant inflammatory reaction by human bronchial epithelial cells. J Clin Gastroenterol 44: 230-235.

8. Zerbib F (2010) Medical treatment of GORD. Emerging therapeutic targets and concepts. Best Pract Res Clin Gastroenterol 24: 937-946.

9. Tutuian R, Mainie I, Agrawal A, Adams D, Castell DO, et al. (2006) Nonacid reflux in patients with chronic cough on acid-suppressive therapy. Chest 130: 386-391.
10. Kaufman JA, Houghland JE, Quiroga E, Cahill M, Pellegrini CA, et al. (2006) Longterm outcomes of laparoscopic antireflux surgery for gastroesophageal reflux disease (GERD)-related airway disorder. Surg Endosc 20: 1824-1830.

11. Kollarik M, Brozmanova M (2009) Cough and gastroesophageal reflux: insights from animal models. Pulm Pharmacol Ther 22: 130-134.

12. Castor JM, Wood RK, Muir AJ, Palmer SM, Shimpi RA (2010) Gastroesophagea reflux and altered motility in lung transplant rejection. Neurogastroenterol Motil 22 841-850.

13. Patterson RN, Johnston BT, Ardill JE, Heaney LG, McGarvey LP (2007) Increased tachykinin levels in induced sputum from asthmatic and cough patients with acid reflux. Thorax 62: 491-495. 